\title{
IMPLICAÇÕES DOS PROCEDIMENTOS CONTÁBEIS PATRIMONIAIS NA GESTÃO DO PATRIMÔNIO PÚBLICO
}

\section{ARTIGO ORIGINAL}

SANTOS, Rômulo de Almeida ${ }^{1}$, SILVA, Igor Ferreira² ${ }^{2}$ SILVA, Juan Carlos Rodrigues $\mathrm{da}^{3}$

SANTOS, Rômulo de Almeida. Et al. Implicações dos procedimentos contábeis patrimoniais na gestão do patrimônio público. Revista Científica Multidisciplinar Núcleo do Conhecimento. Ano 06, Ed. 04, Vol. 05, pp. 77-98. Abril. ISSN: 2448-0959, Link de acesso: https://www.nucleodoconhecimento.com.br/contabilidade/contabeispatrimoniais

\section{RESUMO}

O presente artigo tem por objetivo discutir as implicações dos Procedimentos Contábeis Patrimoniais (PCPs), parte integrante do Manual de Contabilidade Aplicado ao Setor Público (MCASP), na gestão do patrimônio público. Para tal, partiu-se das linhas teóricas da Contabilidade Pública, da estrutura do MCASP, da literatura acerca do patrimônio público e por último dos pontos específicos dos PCPs. Ao longo, são apresentados os diversos entendimentos e conceitos que visam a convergência aos padrões contábeis internacionais. $O$ artigo também explora as mudanças nas normas contábeis que demandaram aos entes do setor público a adequação de novas práticas contábeis e administrativas, encadeando os procedimentos trazidos pelos PCPs, que envolvem a Reavaliação, Redução ao Valor Recuperável, Depreciação, Amortização e Exaustão. Quanto aos procedimentos metodológicos, o artigo adotou dois critérios, o bibliográfico e documental para abordagem conceitual e legal. $O$ artigo é finalizado

\footnotetext{
${ }^{1}$ Graduando Em Administração Pública.

${ }^{2}$ Graduando em Administração Pública.

${ }^{3}$ Graduando em Administração Pública. RC: 82183

Link de acesso: https://www.nucleodoconhecimento.com.br/contabilidade/contabeispatrimoniais
} 
destacando os aspectos inerentes ao Ativo Imobilizado na implantação das práticas dos PCPs no setor público.

Palavras-chave: Procedimentos Contábeis Patrimoniais, Ativo Imobilizado, Manual de Contabilidade Aplicado ao Setor Público.

\section{INTRODUÇÃO}

As diversas questões econômicas em um mercado financeiro globalizado trouxeram a necessidade da convergência de práticas contábeis à padrões internacionais, onde exige-se transparência e eficácia no trato do patrimônio público. Para tal, foi preciso que o país caminhasse rumo à atualização de suas normas contábeis, tanto no setor privado quando no público.

A Contabilidade Pública no Brasil vem passando por diversas transformações desde 2008, quando se iniciou o desenvolvimento das ações de convergência das normas contábeis frente às normas internacionais. Ao longo deste período, foram editados os Pronunciamentos Técnicos pelo Comitê de Pronunciamentos Contábeis, visando, principalmente a uniformização das normas internacionais às brasileiras. Para o setor público, foram criadas as Normas Brasileiras de Contabilidade Técnicas Aplicadas ao Setor Público (NBCs TSP), editadas pelo Conselho Federal de Contabilidade (CFC), as quais apresentam os princípios e conceitos basilares de Contabilidade Pública.

A partir desse ano, diversos normativos foram publicados, tais como a Portaria MF 184/2008, o Decreto №. 6.976/2009, o Manual de Contabilidade Aplicado ao Setor Público (MCASP) e das alterações nas Demonstrações Contábeis Aplicadas ao Setor Público. Tais regulamentos conduzem à perspectiva de que a contabilidade no setor público possa atender à necessidade de fornecer subsídios aos gestores públicos para a tomada de decisão e, principalmente, estabelecer critérios de transparência através de prestações de contas, além de formas eficientes de controle de seus recursos organizacionais. 
Intitulado como Procedimentos Contábeis Patrimoniais (PCPs), este refere-se a um capítulo situado à Parte II do MCASP, ao qual se integram mais quatro partes que tratam desde regras gerais, normas e diretrizes a procedimentos contábeis aplicáveis à todos os entes da federação, visando a consolidação das contas públicas, em âmbito nacional. Acerca dos PCPs, sumariamente, o capítulo versa sobre a harmonização contábil frente às normas internacionais dos procedimentos de registro, classificações e procedimentos reconhecimento, mensuração e evidenciação de ativos, passivos e das variações patrimoniais da entidade pública.

Pereira (2014) destaca que está em curso o processo de ajuste da contabilidade pública brasileira aos padrões internacionais, tendo em vista, a migração da perspectiva orçamentária para o conceito de custo. Nesse entendimento, o enfoque patrimonial ganhou espaço no campo da contabilidade pública, fato que mobilizou diversos setores da administração pública a reformarem suas informações de modo ao atendimento das características qualitativas da informação contábil.

Segundo Brasil (2016, p.25) "as características qualitativas são atributos que tornam a informação útil para os usuários e do suporte ao cumprimento dos objetivos da informação contábil". Sendo assim, tais características objetivam que a informação contábil reflita os atos e fatos administrativos, na perspectiva de possibilitar a prestação de contas, responsabilização (accountability) e tomada de decisão.

A partir dessas premissas, percebe-se que as entidades governamentais possuem a demanda de modernização de seus procedimentos de controle e registro de bens públicos, de modo a estarem em consonância com o modelo de contabilidade pública vigente no país, bem como estarem avaliados de forma correta, de modo a demonstrar valores condizentes com a realidade. Com base nesses argumentos que dimensionam a problemática formulou-se o problema de pesquisa que norteará os objetivos deste estudo. Quais as implicações dos Procedimentos Contábeis Patrimoniais na gestão do Ativo Imobilizado no setor público? 
O estudo se limitará em analisar o problema de pesquisa a partir dos pressupostos legais e teóricos acerca do Ativo Imobilizado, constante dos Procedimentos Contábeis Patrimoniais, módulo do Manual de Contabilidade Aplicada ao Setor Público. A delimitação à tais pontos favorece o entendimento das principais questões a serem descritas na regulamentação dos Procedimentos Contábeis Patrimoniais no setor público para atendimento às mudanças nas normas contábeis.

O presente estudo tem por objetivo principal analisar quais as implicações dos Procedimentos Contábeis Patrimoniais na gestão do Ativo Imobilizado no setor público. Para concretizar tal objetivo, a pesquisa apoia-se no alcance de dois objetivos intermediários:

- Identificar os procedimentos do PCP - Procedimentos Contábeis Patrimoniais relativos ao Ativo Imobilizado constante do MCASP - Manual de Contabilidade Aplicada ao Setor Público;

- Apontar as práticas contábeis-administrativas planejadas em consonância com o Manual de Contabilidade Aplicada ao Setor Público.

Este estudo o estudo explora a temática dos procedimentos de avaliação e mensuração do Ativo Imobilizado como instrumento capaz de municiar o gestor no intuito de provê-lo de informações suficientes sobre a organização que gerenciam, objetivando uma tomada de decisão mais adequada. Assim, visa contribuir para a literatura nacional acerca do que se entende sobre a Nova Contabilidade Aplicada ao Setor Público, tendo em vista, a sua contribuição aos aspectos gerenciais da gestão pública.

A pesquisa também é relevante considerando a situação atual que atravessa a gestão pública brasileira, onde há um quadro de limitação de gastos, necessidade de transparência e cada vez menos recursos disponíveis. Nesse sentido, este trabalho pode contribuir para a ampliação da discussão sobre as considerações contábeis no aspecto gerencial financeiro sobre a eficiência da entidade pública. Adicionalmente, 
possui a importância de salientar novas perspectivas da gestão pública que poderiam ser ampliadas para outras instituições.

Por procedimentos metodológicos, a pesquisa adota dois critérios para a classificação quanto aos meios de investigação: bibliografia e documentos. O primeiro critério consiste na busca por estudos já realizados, literaturas vinculadas à atuação ao Ativo Imobilizado e atualizações sobre o objeto de estudo. O segundo critério visa à investigação da legislação em vigência. Deste modo, será possível uma reflexão contextual entre teoria, atualidade e realidade organizacional, tendo em vista o entendimento da dinâmica governamental frente a adequação à nova normatização contábil.

\section{REFERENCIAL TEÓRICO}

\subsection{CONTABILIDADE PÚBLICA}

Segundo Carvalho (2011, p.1) "a contabilidade é uma ciência social que interpreta o patrimônio das entidades, registrando dados com o objetivo final de prestar informações de forma organizada e focada, [...] demonstrando as mutações ocorridas e os resultados obtidos em determinado período". Nesse sentido, o patrimônio constitui no enfoque central da ciência contábil.

Ainda no entendimento do autor, Carvalho (2011) entende que a contabilidade pública é a ramificação da ciência contábil que trabalha os conceitos, normas e princípios acerca das esferas orçamentária, patrimonial e de custos envolvendo tanto a administração pública direta e indireta objetivando o fornecimento de informações aos seus respectivos usuários.

Em adição, Pereira (2014) contribui que a contabilidade pública vem assumindo um papel de maior relevância no cenário nacional. Isto se dá por fatores como a convergência das práticas de contabilidade pública aos padrões internacionais, bem 
como ao protagonismo da ciência contábil no auxílio à tomada de decisão pelos gestores públicos.

Benites et al. (2017, p.3) destacam a mudança do enfoque orçamentário da contabilidade pública para o patrimonial:

Devido a essa nova visão contábil patrimonial, pois até então a contabilidade pública era focada apenas no seu orçamento, surgiu a necessidade da realização de inventários físicos, avaliação, mensuração, depreciação, dentre outros procedimentos essenciais à evidenciação do real valor dos bens móveis, imóveis e intangíveis das entidades públicas e, para disciplinar essas mudanças, a Secretaria do Tesouro Nacional editou a Portaria ํㅡ 828/2011 estipulando que os procedimentos contábeis patrimoniais deveriam ser adotados gradualmente a partir do exercício de 2012 e integralmente até o término do exercício de 2014 pelas entidades públicas (BENITES et al., 2017, p. 3).

A Secretaria do Tesouro Nacional do Ministério da Fazenda editou o Manual de Contabilidade ao Setor Público (MCASP), que se encontra em sua $7^{a}$ edição, a partir dos instrumentos normativos: Portaria Conjunta STN/SOF no 02, de 22 de dezembro de 2016, Portaria STN oㅛ 840, de 21 de dezembro de 2016. O manual possui validade a partir do exercício 2017 e possui aplicabilidade obrigatória à União, aos estados, Distrito Federal e municípios da federação.

\subsection{MANUAL DE CONTABILIDADE APLICADO AO SETOR PÚBLICO (MCASP)}

O MCASP foi desenvolvido objetivando cumprir três objetivos que são: padronizar os procedimentos contábeis nos níveis de governo existentes, dando suporte e orientação à gestão patrimonial na forma estabelecida pela lei complementar № 101, de 2000, lei de Responsabilidade Fiscal; suprir a necessidade de elaborar demonstrações contábeis consolidadas e padronizadas a base do Plano de Contas Aplicado ao Setor Público, que deve ser utilizado pelos entes federativos conforme portaria MF no 184, de 25 de agosto de 2008; e, por último, de suprir os gestores com a instituição de um instrumento eficiente para orientá-los em seus níveis de governo, 
com a consolidação de regras, conceitos e procedimentos de reconhecimento e apropriação contábil das operações do setor público (BRASIL, 2016).

Ao longo de dez anos de existência, foram sete edições do MCASP, as quais trouxeram avanços à Contabilidade Pública no país. Segundo o Tesouro Nacional, o Manual de Contabilidade Aplicada ao Setor Público objetiva "colaborar com o processo de elaboração e execução do orçamento, além de contribuir para resgatar o objeto da contabilidade como ciência, que é o patrimônio" (BRASIL, 2016, p. 416). Desta forma, tornando-se assim capaz de atender informações requeridas pelos seus usuários, viabilizando a análise das demonstrações contábeis adequadas aos padrões internacionais baseados em um Plano de contas Nacional, sob os aspectos orçamentários, patrimoniais e fiscais.

O MCASP, conforme Portaria STN o 840, de 21 de dezembro de 2016, traz em seu Art. $1^{\circ}$ a composição de sua estrutura, sendo disposto em cinco partes: I - Parte Geral; II - Parte II - Procedimentos Contábeis Patrimoniais (PCP); III - Parte III Procedimentos Contábeis Orçamentários; IV - Parte IV - Plano de Contas Aplicado ao Setor Público; e V - Parte V - Demonstrações Contábeis Aplicadas ao Setor Público. Assim, é possível destacar que o PCP é parte de uma estrutura normativa mais ampla e tem por objetivo o reconhecimento, a mensuração e a evidenciação dos componentes patrimoniais do ente público (BRASIL, 2016).

A Portaria STN no 634, de 19 de novembro de 2013 que dispõe sobre regras gerais acerca das diretrizes, normas e procedimentos contábeis aplicáveis aos entes da Federação, com vistas à consolidação das contas públicas da União, dos estados, do Distrito Federal e dos municípios. O regulamento supra, além de estabelecer normas gerais, traz o conceito acerca dos Procedimentos Contábeis Patrimoniais, bem como os prazos de implantação, conforme seus artigos $6^{\circ}$ e 13 , respectivamente:

Art. 6‥ Os Procedimentos Contábeis Patrimoniais - PCP compreendem o reconhecimento, a mensuração, o registro, a apuração, a avaliação e o controle do patrimônio público (BRASIL, 2013).

RC: 82183

Link de acesso: https://www.nucleodoconhecimento.com.br/contabilidade/contabeispatrimoniais 
Art. 13. Os Procedimentos Contábeis Patrimoniais - PCP, definidos no MCASP e de observância obrigatória pelos entes da Federação, terão prazos finais de implantação estabelecidos de forma gradual por meio de ato normativo da STN (BRASIL, 2013).

No entanto, a adoção do PCP nos entes elencados pela legislação não foi conseguida por dificuldades operacionais e pela falta de recursos materiais e humanos para implantação, em especial aos municípios. Assim, no ano de 2015 foi editado o Plano de Implantação dos Procedimentos Contábeis Patrimoniais, anexo à Portaria STN no 548, de 24 de setembro de 2015, que estabeleceu novos prazos para implantação dos procedimentos, aos quais são descritos no Quadro 1.

Quadro 1: prazos para implantação dos procedimentos patrimoniais

\begin{tabular}{|c|c|c|c|c|}
\hline $\begin{array}{l}\text { PCP (de acordo } \\
\text { com as regras das } \\
\text { NBC TSP e do } \\
\text { MCASP vigentes) }\end{array}$ & $\begin{array}{c}\text { Entes da } \\
\text { Federação }\end{array}$ & $\begin{array}{c}\text { Preparação } \\
\text { de sistemas } \\
\text { e outras } \\
\text { providências } \\
\text { de } \\
\text { implantação } \\
\text { (até) }\end{array}$ & $\begin{array}{l}\text { Obrigatoriedade } \\
\text { dos registros } \\
\text { contábeis } \\
\text { (a partir de) }\end{array}$ & $\begin{array}{c}\text { Verificação } \\
\text { pelo } \\
\text { Siconfi } \\
\text { (a partir } \\
\text { de) }\end{array}$ \\
\hline $\begin{array}{c}7 . \\
\text { Reconhecimento, } \\
\text { mensuração e }\end{array}$ & União & Imediato & Imediato & $\begin{array}{c}2017 \\
\text { (Dados de } \\
2016)\end{array}$ \\
\hline $\begin{array}{l}\text { evidenciação dos } \\
\frac{\text { bens móveis e }}{\underline{\text { imóveis; }}}\end{array}$ & $\begin{array}{c}\text { DF e } \\
\text { Estados }\end{array}$ & $31 / 12 / 2018$ & 01/01/2019 & $\begin{array}{c}2020 \\
\text { (Dados de } \\
\text { 2019) }\end{array}$ \\
\hline $\begin{array}{c}\text { respectiva } \\
\text { depreciação ou } \\
\text { exaustão; } \\
\text { reavaliação e }\end{array}$ & $\begin{array}{l}\text { Municípios } \\
\text { com mais } \\
\text { de } 50 \text { mil } \\
\text { habitantes }\end{array}$ & $31 / 12 / 2019$ & 01/01/2020 & $\begin{array}{c}2021 \\
\text { (Dados de } \\
2020)\end{array}$ \\
\hline
\end{tabular}




\begin{tabular}{|c|c|c|c|c|}
\hline $\begin{array}{c}\begin{array}{c}\text { redução ao valor } \\
\text { recuperável } \\
\text { (exceto bens do } \\
\text { patrimônio } \\
\text { cultural e de } \\
\text { infraestrutura) }\end{array}\end{array}$ & $\begin{array}{l}\text { Municípios } \\
\text { com até } 50 \\
\text { mil } \\
\text { habitantes }\end{array}$ & $31 / 12 / 2020$ & $01 / 01 / 2021$ & $\begin{array}{c}2022 \\
\text { (Dados de } \\
\text { 2021) }\end{array}$ \\
\hline $\begin{array}{c}8 . \\
\text { Reconhecimento, } \\
\text { mensuração e }\end{array}$ & União & $31 / 12 / 2018$ & $01 / 01 / 2019$ & $\begin{array}{c}2020 \\
\text { (Dados de } \\
\text { 2019) }\end{array}$ \\
\hline $\begin{array}{l}\text { evidenciação dos } \\
\underline{\text { bens de }} \\
\text { infraestrutura; }\end{array}$ & $\begin{array}{c}\text { DF e } \\
\text { Estados }\end{array}$ & $31 / 12 / 2021$ & 01/01/2022 & $\begin{array}{c}2023 \\
\text { (Dados de } \\
\text { 2022) }\end{array}$ \\
\hline $\begin{array}{c}\text { respectiva } \\
\text { depreciação, } \\
\text { amortização ou } \\
\text { exaustão; }\end{array}$ & $\begin{array}{l}\text { Municípios } \\
\underline{\text { acima de }} \\
50 \text { mil } \\
\text { habitantes }\end{array}$ & $31 / 12 / 2022$ & $01 / 01 / 2023$ & $\begin{array}{c}2024 \\
\text { (Dados de } \\
\text { 2023) }\end{array}$ \\
\hline $\begin{array}{c}\text { reavaliação e } \\
\text { redução ao valor } \\
\text { recuperável }\end{array}$ & $\begin{array}{l}\text { Municípios } \\
\text { com } \\
\underline{\text { até } 50 \text { mil }} \\
\text { habitantes }\end{array}$ & $31 / 12 / 2023$ & 01/01/2024 & $\begin{array}{c}2025 \\
\text { (Dados de } \\
2024)\end{array}$ \\
\hline $\begin{array}{c}9 . \\
\text { Reconhecimento, } \\
\text { mensuração e }\end{array}$ & União & $31 / 12 / 2020$ & $01 / 01 / 2021$ & $\begin{array}{c}2022 \\
\text { (Dados de } \\
\text { 2021) }\end{array}$ \\
\hline $\begin{array}{l}\text { evidenciação dos } \\
\underline{\text { bens do }} \\
\text { patrimônio }\end{array}$ & $\begin{array}{c}\text { DF e } \\
\text { Estados }\end{array}$ & $31 / 12 / 2021$ & 01/01/2022 & $\begin{array}{c}2023 \\
\text { (Dados de } \\
\text { 2022) }\end{array}$ \\
\hline $\begin{array}{c}\text { cultural; } \\
\text { respectiva } \\
\text { depreciação, }\end{array}$ & $\begin{array}{c}\text { Municípios } \\
\text { acima de }\end{array}$ & $31 / 12 / 2022$ & 01/01/2023 & $\begin{array}{c}2024 \\
\text { (Dados de } \\
2023 \text { ) }\end{array}$ \\
\hline
\end{tabular}

Link de acesso: https://www.nucleodoconhecimento.com.br/contabilidade/contabeispatrimoniais 


\begin{tabular}{|c|c|c|c|c|}
\hline $\begin{array}{c}\text { amortização ou } \\
\text { exaustão; }\end{array}$ & $\begin{array}{c}50 \text { mil } \\
\text { habitantes }\end{array}$ & & & \\
\hline $\begin{array}{l}\text { reavaliação e } \\
\text { redução ao valor } \\
\text { recuperável } \\
\text { (quando passível } \\
\text { de registro } \\
\text { segundo IPSAS, } \\
\text { NBC TSP e } \\
\text { MCASP) }\end{array}$ & $\begin{array}{c}\text { Municípios } \\
\text { com até } 50 \\
\text { mil } \\
\text { habitantes }\end{array}$ & $31 / 12 / 2023$ & $01 / 01 / 2024$ & $\begin{array}{c}2025 \\
\text { (Dados de } \\
2024)\end{array}$ \\
\hline
\end{tabular}

Fonte: Brasil (2015, p. 18).

Brasil (2015) aponta que o MCASP $6^{\text {a }}$ edição traz um tópico específico para tratar dos assuntos do PCP: o capítulo 5 intitulado "Ativo Imobilizado" e o capítulo 7 intitulado "Reavaliação, Redução ao Valor Recuperável, Depreciação, Amortização e Exaustão", ambos da Parte II (Procedimentos Contábeis Patrimoniais), conforme Quadro 2 e Quadro 3.

Quadro 2: Ações dos Procedimentos Contábeis Patrimoniais

\begin{tabular}{|c|c|c|c|}
\hline PCP & $\begin{array}{l}\text { NBC TSP } \\
\text { (em 2015) }\end{array}$ & $\begin{array}{l}\text { MCASP } \quad 6^{a} \\
\text { edição }\end{array}$ & $\begin{array}{l}\text { IPSAS } \\
\text { (em } \\
2015)\end{array}$ \\
\hline $\begin{array}{l}\text { Reconhecimento, mensuração e } \\
\text { evidenciação de bens móveis e imóveis e } \\
\text { da respectiva depreciação, amortização } \\
\text { ou exaustão. }\end{array}$ & $\begin{array}{l}\text { NBC } \quad T \\
16.10 \\
16.2,16.6 \mathrm{e} \\
16.9\end{array}$ & $\begin{array}{l}\text { Capítulos } 5 \text { e } \\
7 \text { da Parte II } \\
\text { (PCP) }\end{array}$ & $\begin{array}{l}\text { IPSAS } \\
17\end{array}$ \\
\hline
\end{tabular}

Fonte: Brasil (2015, p. 17). 
Quadro 3: Conceitos - Procedimentos Contábeis Patrimoniais

\begin{tabular}{|c|c|}
\hline Conceito & Definição \\
\hline Reavaliação & $\begin{array}{l}\text { Adoção do valor de mercado ou de consenso entre as partes para } \\
\text { bens do ativo (CFC, 2008). }\end{array}$ \\
\hline $\begin{array}{l}\text { Redução ao } \\
\text { Valor } \\
\text { Recuperável }\end{array}$ & $\begin{array}{l}\text { É a redução nos benefícios econômicos futuros ou no potencial } \\
\text { de serviços de um ativo, que reflete um declínio na sua utilidade } \\
\text { além do reconhecimento sistemático por meio da depreciação } \\
\text { (BRASIL, 2016, p. 169). }\end{array}$ \\
\hline Depreciação & $\begin{array}{l}\text { É a redução do valor dos bens tangíveis pelo desgaste ou perda } \\
\text { de utilidade por uso, ação da natureza ou obsolescência (BRASIL, } \\
2016, \text { p. 167). }\end{array}$ \\
\hline Amortização & $\begin{array}{l}\text { É a redução do valor aplicado na aquisição de direitos de } \\
\text { propriedade e quaisquer outros, inclusive ativos intangíveis, com } \\
\text { existência ou exercício de duração limitada, ou cujos objeto sejam } \\
\text { bens de utilização por prazo legal ou contratualmente } \\
\text { limitado (BRASIL, 2016, p. 169). }\end{array}$ \\
\hline Exaustão & $\begin{array}{l}\text { É a redução do valor, decorrente da exploração dos recursos } \\
\text { minerais, florestais e outros recursos naturais esgotáveis } \\
\text { (BRASIL, 2016, p. 169). }\end{array}$ \\
\hline
\end{tabular}

Fonte: Brasil (2016); CFC (2008).

No que tange ao Ativo Imobilizado os procedimentos e valores relativos ao ativo imobilizado devem guardar paridade com os do sistema de gestão patrimonial. $\mathrm{Na}$ impossibilidade de integração sistemática, é necessário que o registro contábil possua suporte documental (BRASIL, 2016).

Brasil (2015) destaca que os procedimentos de registro contábil e responsabilidade pelo controle patrimonial são questões distintas e não devem ser confundidas. Por um lado, tem-se as funções de registro contábil da informação patrimonial, de outro, o seu 
controle e gestão. Por equilíbrio, a conciliação patrimonial entre informações lançadas no sistema de patrimônio e o sistema contábil deve ser realizada, preferencialmente, a cada mês no exercício. Nesse entendimento, o tratamento contábil e o controle dos bens patrimoniais, pertencentes ao Ativo Imobilizado torna-se ainda mais relevante no trato da coisa pública.

\subsection{PATRIMÔNIO NA ADMINISTRAÇÃO PÚBLICA}

O conceito de patrimônio, em sentido amplo, representa o "conjunto de bens, direitos e obrigações vinculados a uma pessoa física ou jurídica" (SILVA, 2009, p.117). Em adição, as Normas Brasileiras de Contabilidade (NBCTSP) definem o patrimônio público como o conjunto de direitos e bens, tangíveis ou intangíveis, onerados ou não, adquiridos, formados, produzidos, recebidos, mantidos ou utilizados pelas entidades do setor público, que seja portador ou represente um fluxo de benefícios, presente ou futuro, inerente à prestação de serviços públicos ou à exploração econômica por entidades do setor público e suas obrigações (SILVA, 2009).

Na perspectiva de Silva (2009), esse conjunto de bens constitui no patrimônio estatal, ao qual ao serem incorporados, estão sujeitos à ocorrência de fenômenos que podem alterar o seu valor, a exemplo de depreciações e reavaliações. Assim, o patrimônio do estado é objeto da gestão patrimonial desempenhada pelos órgãos da administração pública.

Em sentido específico, é possível classificar o patrimônio do Estado a partir de dois critérios: o critério jurídico e o critério contábil. Pelo critério jurídico, os bens são classificados em bens de uso comum do povo, bens de uso especial e bens dominicais. Pelo critério contábil, os bens públicos são classificados em: ativo circulante e ativo não circulante (SILVA, 2009).

O ativo circulante compreende as disponibilidades de bens, direitos e valores realizáveis desde que atendam a um dos critérios: disponibilidade para realização imediata; expectativa de realização até o término do exercício seguinte. Já o ativo não RC: 82183

Link de acesso: https://www.nucleodoconhecimento.com.br/contabilidade/contabeispatrimoniais 
circulante envolve todos os demais ativos e incluem os bens, direitos e valores, cuja mobilização ou alienação dependam de autorização legislativa (SILVA, 2009).

Nessa perspectiva, o ativo é, então, um "recurso controlado no presente pela entidade como resultado de evento passado" (COSTA, 2018, p. 696). Logo, uma organização deve possuir formas de controle de seus recursos e conforme demonstra Costa (2018) a entidade deve observar a existências dos seguintes indicadores de controle:

1. a) propriedade legal;

2. b) acesso ao recurso ou à capacidade de negar ou restringir o acesso a esses;

3. c) meios que assegurem que o recurso seja utilizado para alcançar os seus objetivos; ou

4. d) a existência de direito legítimo ao potencial de serviços ou à capacidade para gerar os benefícios econômicos advindos do recurso.

Sendo assim, tais indicadores demonstram a existência de controle sob o aspecto qualitativo e contribuem para o entendimento da capacidade da entidade de utilizar seus recursos para a prestação de serviços ou gerar benefícios econômicos para o cumprimento dos objetivos organizacionais.

Costa (2018) aponta alguns fatores devem ser considerados para estimar a vida útil de um determinado ativo. Na perspectiva do autor, a vida útil econômica deve ser definida com base em parâmetros e índices e após, estar registrado em laudo técnico, conforme demonstrado no Quadro 4. 
Quadro 4: Fatores a considerar para estimar a vida útil de um ativo.

\section{Fatores}

A capacidade de geração de benefícios futuros.

O desgaste físico decorrente de fatores operacionais ou não.

A obsolescência tecnológica.

Os limites legais ou contratuais sobre o uso ou exploração do ativo.

Fonte: Costa (2018).

Em comparação, deve ser citada a Portaria ํㅜ 448 de 13 de setembro de 2002 que trata da divulgação do detalhamento das naturezas de despesas 339030, 339036, 339039 e 449052 . Usualmente reconhecida como parâmetro para apropriação contábil em termos de classificação de itens por elemento de despesa. Em seus anexos, a norma traz categorias e objetos exemplificativos para segmentação nas seguintes naturezas de despesas: 339030 - Material de Consumo, 339036 - Outros Serviços de Terceiros Pessoa Física, 339039 - Outros Serviços de Terceiros Pessoa Jurídica e 449052 - Equipamentos e Material Permanente. A norma, ainda, apresenta os parâmetros excludentes e que devem ser tomados em conjunto para a definição da despesa como material permanente, que pertence ao Ativo Imobilizado.

Art. 3‥ Na classificação da despesa serão adotados os seguintes parâmetros excludentes, tomados em conjunto, para a identificação do material permanente: I - Durabilidade, quando o material em uso normal perde ou tem reduzidas as suas condições de funcionamento, no prazo máximo de dois anos; II - Fragilidade, cuja estrutura esteja sujeita a modificação, por ser quebradiço ou deformável, caracterizando-se pela irrecuperabilidade e/ou perda de sua identidade; III - Perecibilidade, quando sujeito a modificações (químicas ou físicas) ou que se deteriora ou perde sua característica normal de uso; IV Incorporabilidade, quando destinado à incorporação a outro bem, não podendo ser retirado sem prejuízo das características do principal; e V Transformabilidade, quando adquirido para fim de transformação (BRASIL, 2002).

Em entendimento semelhante, a Lei № 4.320/64 trata como pertencente do Ativo Imobilizado os itens com durabilidade maior de dois anos, conforme seu $\S 2^{\circ}$ : "Para 
efeito de classificação da despesa, considera-se material permanente o de duração superior a dois anos" (BRASIL, 1964).

Tanto a Portaria ํㅜ 448/2002 quanto a Lei № 4.320/64 devem ser observadas com cautela pelos agentes públicos nos entes federativos pois, ainda que esteja em vigência apontam critérios obsoletos para a classificação de um bem patrimonial. $O$ MCASP aponta novas conceitos trazidos pela NBC TSP - Estrutura Conceitual que conduzem às mudanças na forma a qual um ativo pode ser definido.

Quadro 5: Conceitos acerca de ativo importadas pela NBC TSP - Estrutura Conceitual.

\section{Conceituações trazidas pela NBC TSP - Estrutura Conceitual}

Ativo: recurso controlado no presente pela entidade como resultado de evento passado;

Recurso: item com potencial de serviços ou capacidade de gerar benefícios econômicos;

Potencial de serviços: capacidade de prestar serviços que contribuam para alcançar os objetivos da entidade;

Fonte: Adaptado de Brasil (2016, p. 141-142).

Datada de 2002, a Portaria № 448/2002 deve ser observada com cautela pelos agentes públicos nos entes federativos pois, ainda que esteja em vigência aponta critério obsoletos para a classificação de um bem patrimonial. O MCASP aponta novas conceitos trazidos pela NBC TSP - Estrutura Conceitual que conduzem a mudanças na forma a qual um ativo pode ser classificado. Esta perspectiva é, por fim, corroborada por Silva $(2009$, p. 133) que destaca que este critério "precisa ser repensado, vez que para a ciência contábil deve prevalecer a ideia de ativo como elemento voltado para a geração de fluxos de caixa futuros e não em função da durabilidade, do valor ou do prazo de vida útil". 


\subsection{PROCEDIMENTOS CONTÁBEIS PATRIMONIAIS}

Aspectos importantes relativo ao Ativo Imobilizado foram trazidos pela MCASP. Em especial na Parte II - Procedimentos Contábeis Patrimoniais, o manual orienta antes do ente federativo realizar os PCPs deve proceder a adoção do ajuste dos bens à valor justo, tendo em vista a não realização anterior dos procedimentos de depreciação, reavaliação e redução a valor recuperável. Tal ajuste não deve ser considerado como reavaliação, deve ser apenas ação contábil prévia de ajuste de exercícios anteriores para adequação à realidade dos valores dos bens patrimoniais.

\subsubsection{REAVALIAÇÃO E REDUÇÃO A VALOR RECUPERÁVEL}

O MCASP disserta que são diversos os fatores que podem fazer com que o valor contábil de um ativo não corresponda ao seu valor justo. Nesse sentido, se após o reconhecimento inicial de uma classe de ativo imobilizado ou intangível a entidade adotar esse método de mensuração, é necessário que esses bens passem por um procedimento visando adequar o seu valor contábil ao seu valor justo regularmente (BRASIL, 2016). Assim, a norma supra traz aspectos relevantes a serem observados quanto ao procedimento de reavaliação patrimonial.

Quadro 6: Aspectos relevantes no procedimento de reavaliação.

\section{Aspectos relevantes}

Quando um item do ativo imobilizado é reavaliado, a depreciação acumulada na data da reavaliação deve ser eliminada contra o valor contábil bruto do ativo, atualizando-se o seu valor líquido pelo valor reavaliado.

O valor do ajuste decorrente da atualização ou da eliminação da depreciação acumulada faz parte do aumento ou da diminuição no valor contábil registrado.

Caso um item do ativo imobilizado seja reavaliado, é necessário que toda a classe de contas do ativo imobilizado à qual pertence seja reavaliado.

Fonte: Brasil (2016, p. 182).

RC: 82183

Link de acesso: https://www.nucleodoconhecimento.com.br/contabilidade/contabeispatrimoniais 
Acerca do método de aplicação do procedimento de reavaliação, Benites et al. (2017) aponta que não há normatizado um método para a avaliação do ativo imobilizado, sendo utilizado a base de cálculo idealizado por Barbosa (2013), a qual estabelece uma equação para retorno de um Fator de Reavaliação (FR). Para cálculo deste fator se faz necessário a ponderação de três critérios a saber: Estado de conservação (EC); Período de vida útil futura (PVU) e Período de utilização do bem (PUB) e após a soma da valorização de cada um dos fatores de influência, multiplicados cada qual por seu respectivo peso conforme pontuação atribuída através do Quadro 8, dividindo-se o total por 100. Assim, considera-se a seguinte equação, conforme Quadro 7:

Quadro 7: Componentes da Equação do Fator de Reavaliação (FR).

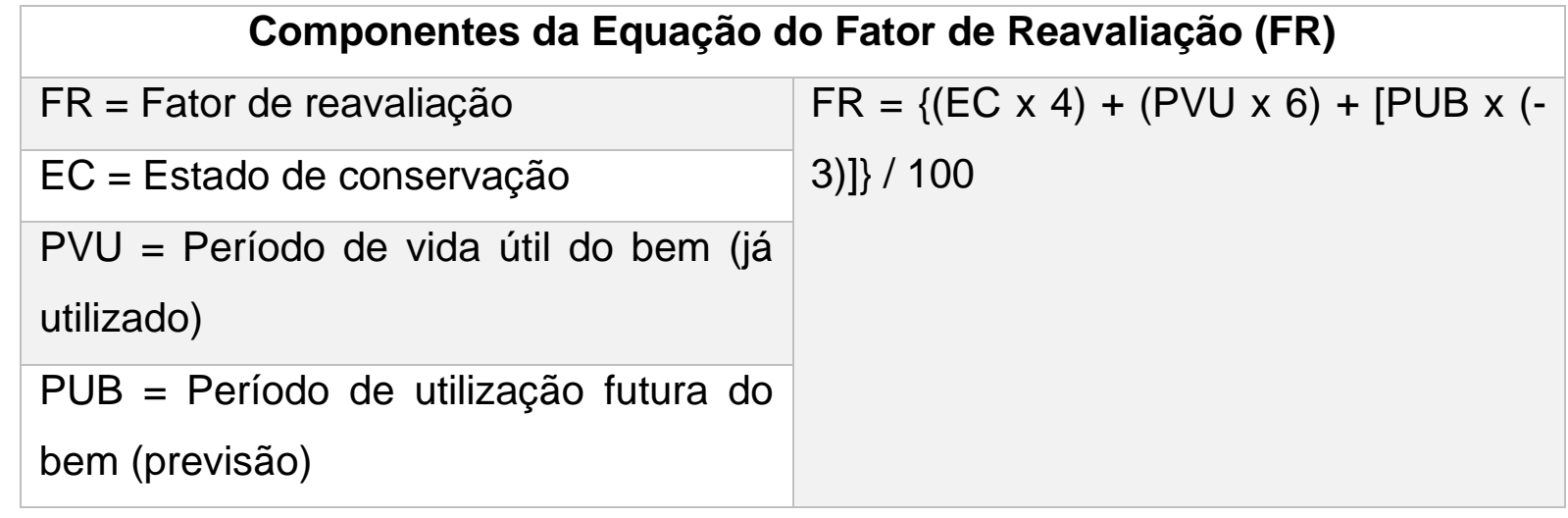

Fonte: Barbosa (2013). 
Quadro 8: Fatores de Influência.

\begin{tabular}{|c|c|c|c|c|c|}
\hline \multicolumn{6}{|c|}{ Fatores de Influência } \\
\hline \multicolumn{2}{|c|}{$\begin{array}{c}\text { Estado de Conservação } \\
\text { do Bem - EC }\end{array}$} & \multicolumn{2}{|c|}{$\begin{array}{l}\text { Período de vida útil } \\
\text { futura (PVU) }\end{array}$} & \multicolumn{2}{|c|}{$\begin{array}{l}\text { Período de utilização do } \\
\text { bem (PUB) }\end{array}$} \\
\hline Conceito & Pontuação & Conceito & Pontuação & Conceito & Pontuação \\
\hline Excelente & 10 & 10 anos & 1 & 10 anos & 1 \\
\hline Bom & 8 & 9 anos & 2 & 9 anos & 2 \\
\hline Regular & 5 & 8 anos & 3 & 8 anos & 3 \\
\hline \multirow[t]{7}{*}{ Péssimo } & 2 & 7 anos & 4 & 7 anos & 4 \\
\hline & & 6 anos & 5 & 6 anos & 5 \\
\hline & & 5 anos & 6 & 5 anos & 6 \\
\hline & & 4 anos & 7 & 4 anos & 7 \\
\hline & & 3 anos & 8 & 3 anos & 8 \\
\hline & & 2 anos & 9 & 2 anos & 9 \\
\hline & & 1 ano & 10 & 1 ano & 10 \\
\hline
\end{tabular}

Fonte: Benites et al. (2017, p.7) apud Barbosa (2013). 
Quadro 9: Fatores de Influência.

\section{Fatores de Influência}

\begin{tabular}{|c|c|c|}
\hline $\begin{array}{c}\text { Estado de } \\
\text { conservação }\end{array}$ & Características & Valoração \\
\hline Péssimo & $\begin{array}{c}\text { Apresenta defeitos, falhas ou desgaste } \\
\text { acentuados, todavia, podendo ainda servir à sua } \\
\text { finalidade, mediante recuperação economicamente } \\
\text { vantajosa. }\end{array}$ & 2 \\
\hline Regular & $\begin{array}{l}\text { Apresenta pequenos defeitos, falhas ou leve } \\
\text { desgaste, ainda servindo à sua finalidade, podendo } \\
\text { ser facilmente recuperado. }\end{array}$ & 5 \\
\hline Bom & $\begin{array}{l}\text { Não apresenta defeitos ou falhas evidentes, } \\
\text { apenas pequeno desgaste, servindo plenamente à } \\
\text { finalidade para qual foi adquirido. }\end{array}$ & 8 \\
\hline Excelente & $\begin{array}{c}\text { Bem novo ou em perfeitas condições de uso, não } \\
\text { apresentando quaisquer falhas, defeitos ou } \\
\text { desgaste. }\end{array}$ & 10 \\
\hline
\end{tabular}

Fonte: Barbosa (2013).

Quadro 10: Pesos de fatores de Influência.

\begin{tabular}{|l|l|}
\hline Fator de Influência & Peso Aplicável \\
\hline Estado de conservação do bem (EC) & 4 \\
\hline Período de vida útil do bem (já utilizado) (PVU) & 6 \\
\hline Período de utilização futura do bem (previsão) (PUB) & -3 \\
\hline
\end{tabular}

Fonte: Barbosa (2013).

Nesse sentido, os Quadros 7 ao 10 demonstram os fatores e critérios aos quais compõem a equação do Fator de Reavaliação (FR). Após seu cálculo, o Fator de RC: 82183

Link de acesso: https://www.nucleodoconhecimento.com.br/contabilidade/contabeispatrimoniais 
Reavaliação (FR) será necessário a obtenção de valor de mercado de um bem novo idêntico ou similar, ao qual seu valor será multiplicado e resultará no valor de reavaliação conforme equação no Quadro 11.

Quadro 11: Equação do Valor de Reavaliação ou Redução ao Valor Recuperável.

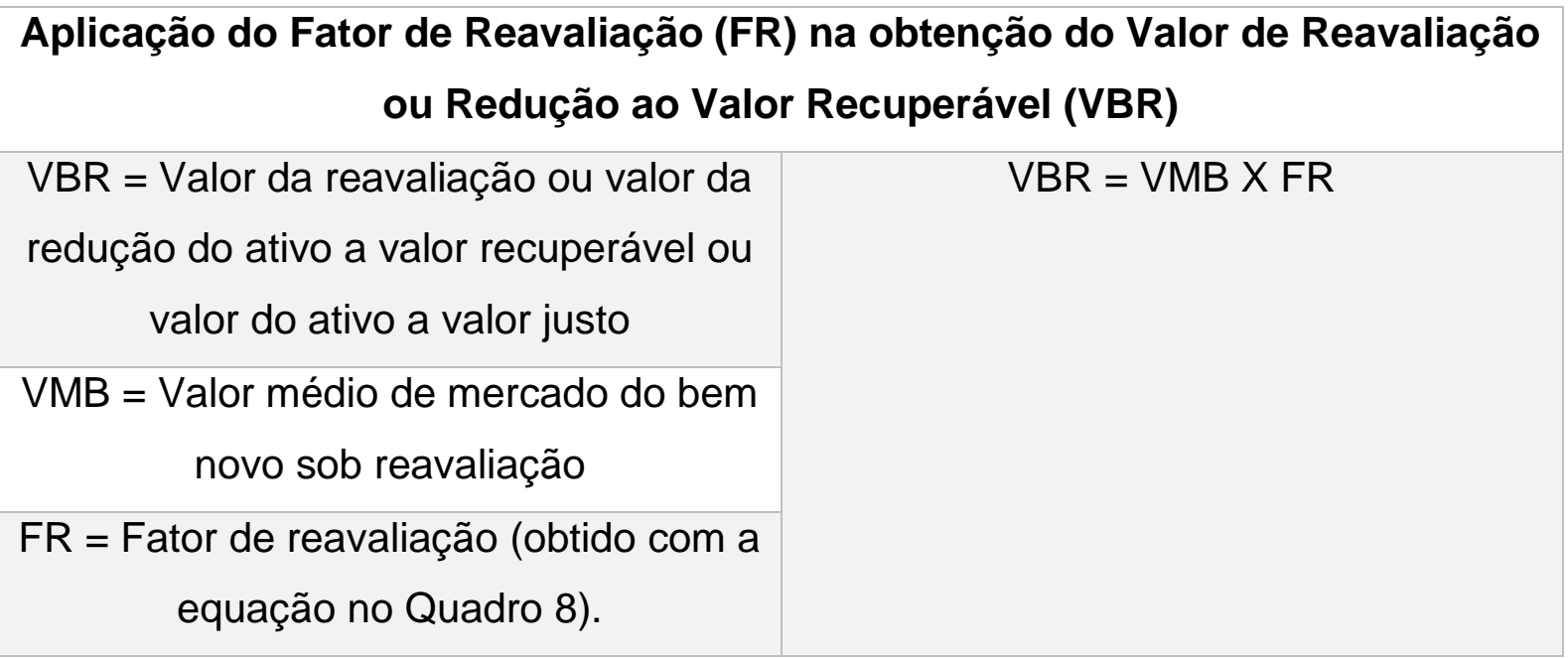

Fonte: Barbosa (2013).

Segundo Brasil (2018) o procedimento de reavaliação poderá ser realizado por perito, empresa especializada ou por comissão composta por servidores do órgão. Em todas as situações deverá ser lavrado um laudo técnico, ao qual será o suporte documental que subsidiará os registros contábeis. O laudo técnico ou relatório de reavaliação deverá possuir, no mínimo, as seguintes informações:

a. Documentação com a descrição detalhada referente a cada bem que esteja sendo avaliado;

b. A identificação contábil do bem;

c. Quais foram os critérios utilizados para avaliação do bem e sua respectiva fundamentação;

d. Vida útil remanescente do bem, para que sejam estabelecidos os critérios de depreciação ou de exaustão;

e. Data de avaliação; e

RC: 82183

Link de acesso: https://www.nucleodoconhecimento.com.br/contabilidade/contabeis- 
f. A identificação do responsável pela reavaliação.

(BRASIL, 2018, p. 176).

De posse da informação supra, a comissão designada, organização ou profissional contratado para a execução do procedimento de reavaliação poderá exportar os dados coletados para um software de planilha eletrônica ou sistema de informação que processará a informação e calculará o valor do bem reavaliado, conforme exemplificado no Quadro 12.

Quadro 12: Exemplo de aplicação de procedimento de Reavaliação.

\section{Exemplo de Aplicação}

1. Supondo-se um bem pertencente à Conta Contábil 1.2.3.1.1.03.03.00.00.00 (Mobiliário em Geral) com as seguintes características:

a) Incorporação: 03.10.2016;

b) Valor de aquisição: $R \$ 1.500,00$

c) Estado de Conservação (EC): Excelente;

e) Período de vida útil do bem (PVU): 2 anos;

d) Período de utilização futura do bem (PUB): 8 anos;

f) Valor de referência de mercado do bem (VMB): $R \$ 1.700,00$.

1.1 Para se chegar ao seu valor de reavaliação, precisa-se primeiramente, calcular seu Fator de Reavaliação (FR), conforme definição na Equação 1. Assim, consultando, nas tabelas do Anexo I, a valorização dada a cada fator de influência do bem, chega-se às variáveis: $E C=10, P V U=6, P U B=1$

Pode-se, agora, passar ao cálculo da Equação 1: 
$F R=\{(E C \times 4)+(P V U \times 6)+[P U B \times(-3)]\} / 100$

$\mathrm{FR}=\{(10 \times 4)+(9 \times 6)+[3 \times(-3)]\} / 100=(40+54-9) / 100=0,85$

1.2. Uma vez determinado o valor de FR passa-se, finalmente, ao cálculo da Eq. 2.

Assim, considerando $\mathrm{VMB}=\mathrm{R} \$ 1.700,00$ e $\mathrm{FR}=0,85$, tem-se por valor de reavaliação $(\mathrm{VBR})=1.700 \times 0,85=\mathrm{R} \$ 1.445,00$.

Portanto, o valor final de reavaliação final do bem ou valor justo será $R \$ 1.445,00$.

Fonte: Elaborado pelo autor.

Costa (2018) destaca que a reavaliação pode ser positiva ou negativa. Kohama (2014, p. 250) corrobora que "as reavaliações dos bens móveis e imóveis, de que trata a lei, pode ser aplicada no sentido de procedimentos para valorização, como também de procedimentos relativos à depreciação ou desvalorização dos bens móveis e imóveis". Nesse sentido, o cálculo da reavaliação pode trazer valorização ou desvalorização ao bem e deverá ser contabilizada da seguinte forma: 
Quadro 13: Registros contábeis resultantes da Reavaliação

\section{Registros Contábeis da Reavaliação}

\begin{tabular}{|c|c|}
\hline Reavaliação positiva & Reavaliação negativa \\
\hline $\begin{array}{l}\text { Variação Patrimonial Aumentativa } \\
\text { (VPA) }\end{array}$ & Variação Patrimonial Diminutiva (VPD) \\
\hline $\begin{array}{l}\text { D 1.2.3.X.X.XX.XX Ativo Imobilizado } \\
\text { C 4.6.1.X.1.XX.00 Reavaliação de }\end{array}$ & $\begin{array}{l}\text { D 3.6.1.X.1.XX.00 Redução ao Valor } \\
\text { Recuperável Imobilizado/Intangíveis }\end{array}$ \\
\hline Bens Imóveis, Móveis ou Intangíveis & $\begin{array}{l}\text { C 1.2.X.9.1.XX.00 (-) Redução ao Valor } \\
\text { Recuperável Imobilizado/Intangíveis }\end{array}$ \\
\hline Aumenta o Resultado Patrir & $\begin{array}{l}\text { Diminui o Ativo e o Patrimônio Líquido, por } \\
\text { meio da redução do resultado do exercício }\end{array}$ \\
\hline
\end{tabular}

Fonte: Adaptado de Brasil (2014, p. 24).

Por fim, Costa (2018, p. 1205) afirma que "a redução ao valor recuperável não deve ser confundida com a depreciação". No entendimento do autor, a depreciação está relacionada ao "declínio gradual do potencial de geração de serviços por ativo de longa duração, ou seja, a perda do potencial de benefícios de um ativo motivada pelo desgaste, uso, ação da natureza ou obsolescência". Por outro lado, a reavaliação resulta de evento que causa perda no valor do ativo.

\subsubsection{DEPRECIAÇÃO, AMORTIZAÇÃO E EXAUSTÃO}

Segundo Brasil (2018), a depreciação, a amortização ou a exaustão de um ativo começa quando o item estiver em condições de uso, devendo ser realizada mensalmente e representará um duodécimo da taxa de depreciação anual do bem. Deve o ente, ainda, planejar antes de aplicar os procedimentos, bem como prestar as respectivas informações em Notas Explicativas: o método, a vida útil do bem e a taxa utilizada; o valor contábil bruto e a depreciação acumulada no início e no fim; as 
mudanças nas estimativas em relação aos valores residuais, vida útil, método e taxas utilizadas no processo (COSTA, 2018).

Determinados bens não são passíveis à depreciação. O Quadro 14 demonstra as categorias as quais não estão sujeitas a tal procedimento, em função de suas características.

Quadro 14: Classificação de bens não sujeitas ao regime de depreciação.

\section{Ativos}

Bens móveis de natureza cultural, tais como obras de artes, antiguidades, documentos, bens com interesse histórico, bens integrados em coleções, entre outros.

Bens de uso comum que absorveram ou absorvem recursos públicos, considerados tecnicamente de vida útil indeterminada.

Animais que se destinam à exposição e à preservação.

Terrenos rurais e urbanos.

Fonte: Costa (2018, p. 1177-1178).

Consoante aos procedimentos de depreciação, amortização e exaustão, Costa (2018, p. 1176) destaca que "o valor depreciado, amortizado ou exaurido, apurado mensalmente, deve ser reconhecido nas contas de resultado do exercício". Nesse sentido, independentemente do método de depreciação utilizado pelo entende, deverão ser realizados os registros contábeis constantes do Quadro 15.

Quadro 15: Registros contábeis resultantes da Depreciação, Amortização e Exaustão.

\section{Registros Contábeis da Depreciação, Amortização e Exaustão}

Demonstração das

Variações Patrimoniais

(DVP)

Link de acesso: https://www.nucleodoconhecimento.com.br/contabilidade/contabeis- 


\begin{tabular}{|c|c|}
\hline $\begin{array}{c}\text { Variação Patrimonial } \\
\text { Diminutiva (VPD) }\end{array}$ & Conta Retificadora do Ativo \\
\hline 3.3.3.x.x.xx.xx & 1.2.x.x.x.xx.xx \\
$\begin{array}{c}\text { Depreciação, Exaustão e } \\
\text { Amortização } \\
\text { Diminui o Resultado } \\
\text { Patrimonial }\end{array}$ & $\begin{array}{c}\text { Diminui o Ativo e o Patrimônio Líquido, por meio } \\
\text { da redução do resultado do exercício }\end{array}$ \\
\hline
\end{tabular}

Fonte: Brasil (2018, p. 180).

Finalmente, ainda que o MCASP e os PCPs sejam explicativos quanto às orientações de aplicação dos procedimentos, ainda se torna complexa a sua plena aplicação, principalmente em âmbito municipal. As atualizações das normas exigem adaptação dos profissionais contabilistas e administrativos, tendo em vista que a Nova Contabilidade Pública trouxe novas perspectivas para as informações contábeis no âmbito da Administração Pública.

\section{CONSIDERAÇÕES FINAIS}

Considerando as abordagens teóricas acerca da Contabilidade Públicas e os normativos relacionados, é possível salientar que o processo de convergência às normas internacionais estabelecido a partir de 2008 trouxeram às administrações públicas, do nível federal ao municipal, a necessidade de coordenação de ações com vistas à implementação de novas rotinas administrativas e contábeis delineados pelo MCASP objetivando a qualidade e a consistência das informações públicas prestadas à sociedade.

O primeiro passo para iniciar o estudo em questão foi identificar os procedimentos do PCP - Procedimentos Contábeis Patrimoniais relativos ao Ativo Imobilizado, constantes da Parte II do MCASP $7^{\text {a }}$ Edição. O referido manual é elemento constante da Portaria STN o 840, de 21 de dezembro de 2016, a qual aprovou o MCASP em RC: 82183

Link de acesso: https://www.nucleodoconhecimento.com.br/contabilidade/contabeispatrimoniais 
sua 7a edição. Assim, é possível destacar que o PCP é parte de uma estrutura normativa mais ampla e tem por objetivo o reconhecimento, a mensuração e a evidenciação dos componentes patrimoniais do ente público.

Quanto as práticas contábeis-administrativas orientadas pela norma supra, as principais ações resumem-se à adoção de reavaliação, depreciação, amortização e redução ao valor recuperável. Práticas estas que, anteriormente, não eram obrigatórias pela Lei no 4.320/64, que estatui Normas Gerais de Direito Financeiro para elaboração e controle dos orçamentos e balanços da União, dos Estados, dos Municípios e do Distrito Federal. A adequação destes novos procedimentos está estritamente relacionada à convergência aos padrões internacionais de contabilidade.

Por fim, cabe mencionar que a adoção de tais procedimento traz a necessidade de mudança de cultura organizacional nas administrações públicas, pois envolve a demanda de desenvolvimento de atualização e conhecimento técnico pelos gestores e servidores. Tal dificuldade é perceptível em escala nacional, tendo em vista a ausência de profissionais qualificados, principalmente em municípios com menos de 50 mil habitantes. É nesta perspectiva que o prazo a tais entes federativos foi alongado. O prazo para adoção total dos PCPs ainda está em curso e este estudo poderá servir de material para entender o processo de implantação no setor público.

\section{REFERÊNCIAS}

BENITES, Mauren Corrêa dos Santos; CASTRO, Roberta Graziella Vivian; CUNICO, Geisa. $\mathrm{O}$ impacto contábil da avaliação patrimonial dos bens móveis do setor de contas e cadastro do Departamento De Água e Esgotos de Santana do Livramento-RS. In XVI CONVENÇÃO DE CONTABILIDADE DO RIO GRANDE DO SUL, 13 a 15 de setembro de 2017 - Gramado-RS.

BARBOSA, Diogo Duarte. Manual de controle patrimonial nas entidades Públicas. 1. ed. Brasília: Gestão Pública Ed., 2013. 
BRASIL. Lei o 4.320 de 17 de março de 1964. Estatui Normas Gerais de Direito Financeiro para Elaboração e Controle dos Orçamentos e Balanços da União, dos Estados, dos Municípios e do Distrito Federal. Disponível em: < http://www.planalto.gov.br/ccivil_03/leis/14320.htm>. Acesso em: 31 mar. 2016.

. Manual de contabilidade aplicada ao setor público. - 7. ed. 2016 Disponível em: <http://www.tesouro.fazenda.gov.br/documents/10180/456785/MCASP+7\%C2\%AA \%20edi\%C3\%A7\%C3\%A30+Vers\%C3\%A3o+Final.pdf/6e874adb-44d7-490c-8967b0acd3923f6d >. Acesso em: 17 de dezembro de 2018.

. Manual de contabilidade aplicada ao setor público. - 8. ed. 2018 Disponível em: http://www.tesouro.fazenda.gov.br/documents/10180/695350/CPU_MCASP+8\%C2\% AA\%20ed+-+publica\%C3\%A7\%C3\%A3o_com+capa_3vs_Errata1/6bb7de01-39b44e79-b909-6b7a8197afc9 >. Acesso em: 20 de abril de 2019.

. Plano de Implantação dos Procedimentos Contábeis Patrimoniais (Anexo à Portaria STN no 548, de 24 de setembro de 2015). Disponível em: $<$ https://www.tesouro.fazenda.gov.br/documents/10180/390684/Portaria-STN-5482015-anexo-pipcp/331a2764-dc97-473a-82b0-deb3cdd2380f>. Acesso em 17 de dezembro de 2018.

Portaria STN № 448, de 13 de setembro de 2002. <http://portalfns.saude.gov.br/images/banners/Sigem/Portaria_448_de_13_de_Sete mbro_de_2002.pdf $>$. Acesso em 14 de abril de 2019.

Portaria STN № 634, de 19 de novembro de 2013. <http://www3.tesouro.gov.br/legislacao/download/contabilidade/Portaria_STN_634_2 013_Processo_Convergencia.pdf>. Acesso em 17 de dezembro de 2018. 
Rotinas e Procedimentos Contábeis da União - Parte V - Estoques E Imobilizado.

$<$ http://www.tesouro.fazenda.gov.br/documents/10180/360403/Estoques+e+Amoxarif a do+25_08_2014.pdf/2d449c3d-59a0-4b54-948a-6e814a261385>. Acesso em 06 de maio de 2019.

CARVALHO, Deusvaldo; CECCATO, Márcio. Manual Completo de Contabilidade Pública. 1ª Ed. Rio de Janeiro: Elsevier, 2011.

CONSELHO FEDERAL DE CONTABILIDADE. Resolução no 1.136, de 21 de novembro de 2008. Aprova a NBC T 16.09 - Avaliação e Mensuração de Ativos e Passivos em Entidades do Setor Público. Disponível em: <http://www1.cfc.org.br/sisweb/SRE/docs/RES_1136.pdf>. Acesso em: 17 de dezembro de 2018.

. Resolução no 1.137, de 21 de novembro de 2008. Aprova a NBC T 16.10 Avaliação e Mensuração de Ativos e Passivos em Entidades do Setor Público. Disponível em: <http://www1.cfc.org.br/sisweb/SRE/docs/RES_1137.pdf>. Acesso em: 17 de dezembro de 2018.

COSTA, Giovanni Pacelli Carvalho Lustosa da. Contabilidade Pública 3D. Salvador: Editora Juspodivm, 2018. 1488 p.

KOHAMA, Heilio. Contabilidade pública: teoria e prática.14 ed. São Paulo: Atlas, 2014

PEREIRA, José Matias. Curso de Administração Pública: foco nas instituições e ações governamentais. 4 ed. São Paulo: Atlas, 2014.

SILVA, Lino Martins da. Contabilidade Governamental: Um Enfoque Administrativo da nova Contabilidade Pública. 8. ed. São Paulo: Atlas, 2009.

Enviado: Janeiro, 2021.

RC: 82183

Link de acesso: https://www.nucleodoconhecimento.com.br/contabilidade/contabeis-

patrimoniais 
Aprovado: Abril, 2021. 